\title{
Clinics in diagnostic imaging (180)
}

Tan EJ, Moey T, Madhukumar P, Leong LC

Singapore Med J 2017; 58(10): 585-592; doi: 10.11622/smedj.2017098

The term 'granulation mastitis' should have been 'granulomatous mastitis' in the following places: (1) page 587, right column, in lines 4 and 15; and (2) page 589 in the legend of Fig. 11.

doi: 10.11622/smedj.2017112 